\title{
Gender and Positive Politeness in Facebook Communication
}

\author{
Marta Dabrowska \\ Jagiellonian University
}

\begin{abstract}
$\mathrm{T}$ he current paper is a contribution to the discussion in progress for about forty years which concerns the existence of possible differences in the speaking styles of women and men, initiated on a more global scale by the publication of a seminal paper by R. Lakoff (1975). The main thesis of her paper could be summed up in brief by a statement that women's language is deficient, as it is (according to the author) characterised by a number of features indicating that women speak from a position of powerless persons. More specifically, they tend to be excessively polite (which manifests itself through a large number of standard language forms, hedges, question tags, and questions), they show lack of confidence in what they are saying due to a frequent use of the hesitant, rising intonation. What is more, their language is overly affective as they often "speak in italics", and what they say lacks substance, which is visible in the high frequency of the so called "empty" adjectives, as e.g. cute, lovely, etc.

The above statements have proved quite controversial to both men and women, which has led to extensive research into male-female linguistic differences (more than similarities, for obvious reasons). This, in turn, has generated a wealth of data and has been able to bring in new perspectives, especially as far as the language used by women is concerned, moreover, in many cases it has disproved Lakoff's original claims. A fairly long list of differences in terms of male and female speaking styles could be drafted as a result, especially as regards the use of language in interaction, e.g., a much greater tendency to interrupt their interlocutors, to occupy a longer speaking time, and to initiate the subjects of conversation on the part of men, a different meaning and frequency of the use of backchannel noises in the speech of the two genders, the character and the meaning of hedges and question tags, the male preference for generalisation as opposed to the female personalisation, and indeed, among others, a greater tendency to resort to polite forms of language on the part of women (cf. Swann 2000; Stockwell 2002). The latter feature, among others, has particularly been singled out by feminist researchers who have analysed single-sex interactions (viz. Coates 1993; Cameron 1995), as a result of which a new approach towards specifically the female style of speaking has been proposed following the assumption that when interacting women employ a cooperative style of communication and support each other. This goal can indeed be achieved by means of the above-mentioned features of the female genderlect, and the polite style of speaking occupies a prominent position among them.

The above processes progressed parallel to the developments in the study of linguistic politeness, which has featured a number of influential approaches to date (viz. Leech 1980; 1983; Fraser 1990; Janney and Arndt 1992), but the study which has proved most seminal is that of Brown and Levinson (1987/1994). Brown and Levinson's research adopted Goffman's (1967) concept of face as its foundation, as a result of which the
\end{abstract}


notion of a Face Threatening Act, a speech act which can potentially be threatening to both the hearer's and/or the speaker's face, was developed, and this, in turn led to the distinction between four types of polite behaviour. And thus, depending on the intention of the speaker behind a given speech act and the communicative strategies used, the authors distinguished bald on-record politeness (most face-threatening, as it aims for the clarity of expression more than showing attention to the addressee's feelings), off record politeness (most difficult to interpret, as the speaker uses many evasive methods in order to express his or her meaning indirectly), on-record negative politeness (the one which is most identified with the traditional concept of speaking politely, and one which attends to the hearer's negative face needs, i.e. the needs to be respected, unimpeded in one's actions, etc.), and finally on-record positive politeness, i.e. one which is directed towards the hearer's positive face needs, i.e. his or her wish to be accepted, liked, admired. It is the latter type of politeness that I wish to elaborate on in the context of the genderlect discussion. Positive politeness makes use of a number of strategies which allow one to attend to the hearer's positive face, most typical of which would be, e.g., intensifying interest in the hearer, asserting common ground, using in-group identity markers, promising, giving gifts, seeking agreement, being optimistic, to name just a few. These may be implemented by means of more specifically defined speech acts, as thanks, offers, invitations, compliments, etc. (cf. Brown and Levinson 1987/1994). This type of politeness, as indicated above, has been mostly identified with the female style of speaking, which has been confirmed by a number of subsequent studies motivated by Lakoff's paper (cf. Tannen's rapport talk (1990), Holmes's affective speaking (1993, 1995), Coates's (1993) and Cameron's (1995) studies of all-female interaction).

The traditional genderlect studies naturally have focused on the spoken medium most, i.e. on face-to-face interaction. The purpose of the current study is to examine some real language samples generated by a new study context which is the Computer Mediated Communication, according to some linguists possibly as a separate channel from speech and writing (viz. Stockwell 2002). I have already studied different aspects of genderlects in the context of email (viz. Dąbrowska 2007a, d, e). Examined here will be the CMC context of a social network, represented by Facebook. The main goal will be to establish whether women indeed do have a greater tendency than men to resort to positive politeness in the semi-formal and informal language context, and if so, which strategies, if any, appear to be most popular among the language users. The study will be based on language samples collected among native British English Facebook users, so that integrity of the study assumptions and findings can thus be maintained. In view of the latest observations made in the context of genderlect studies it is believed that in order to make any justified comments about the two speaking styles, one needs to focus on the language of fairly well defined language communities, and not merely make some vague and sweeping statements about all men and all women (cf. Bing and Bergvall 1996; Mills 2003). Hence my choice of the native British English Facebook users. Firstly, it is the most numerous group I interact with by means of Facebook, which allows me to investigate the language samples of persons from different generations, and secondly, the studies of genderlects have focused extensively on the speakers of English, mainly its American, 
British, New Zealand and Australian variants (cf. Lakoff 1975; Tannen 1990; Holmes 1993, 1995; Coates 1993; Cameron 1995; Eisikovits 1987, 1988), thanks to which it will be possible to verify my findings against the already available knowledge.

As far as the choice of the medium for the selection of the language samples is concerned, as I have already stated in my former papers concerning the analysis of the Facebook data (cf. Dąbrowska 2011 and forthcoming), I believe that, due to its worldwide recognition, social networks, and notably Facebook, contain a wealth of most natural, informal and semi-formal language samples which are available in large quantities for a sociolinguistic study. Facebook creates a friendly, encouraging environment in which the users want to share their thoughts, feelings and experiences with their friends and acquaintances in a safe context, they also want to discover similar things about their Facebook contacts. My assumption is, therefore, that focus is placed more on the social aspect of interaction rather than on the referential one. For this reason Facebook is a source of predominantly naturally occurring language, though obviously modified up to a point by the fact that it does, after all, make use of writing, writing that will be read by many, which in the case of some users may evoke a greater attention to the language correctness. Another important reason behind the choice of Facebook as a source of data is the fact that it is a form of CMC whose main purpose is to maintain contacts with other people. This may be done by sharing some factual information and initiating a discussion on some issues or events happening in the world, but more often than not it is a space where one shares personal information and expects the same from their network contacts - it is a medium which enhances positive relationships with people, and as such it also serves as a very valuable source of data concerning the phatic aspect of human communication. Politeness, and particularly the on record positive politeness has a very integral part in how we want to nurture our contacts with others. Showing our friends and acquaintances that we care about them, like or admire them as well as their views, experiences, etc. is a vital part of building and maintaining friendships and enhancing good relations with people. We often attend to the other's positive face because we expect the same in return. My assumption is therefore that a number of language samples collected through the Facebook medium will serve as positive politeness carriers and as such will generate data which will allow me to explore the gender-related aspects of language use more thoroughly.

The samples analysed here have been collected among the posts generated by 24 users of Facebook, all of them native speakers of English from Great Britain. The figure, albeit not very high, comprises 12 female and 12 male users, and each of the groups is composed of four young persons (aged between 20-35), four middle-aged (aged between 36-55) and four senior ones (aged 56 and more), thereby allowing for a fairly balanced representation of the two genders as exemplified by various age groups. It is obvious that each user possesses some unique characteristics, however, it is believed that certain common traits and behavioural tendencies can still be found across the gender and age groups. The samples were as a rule collected from among posts written in the course of one month, although there were a few exceptions of longer periods in the case of the persons who are not very avid Facebook users. The examination of altogether 192 posts in search for the manifestations of positive politeness (96 posts for each group) allowed me 
to identify 260 examples of speech acts which could be recognised as carriers of positive politeness. More specifically, there were 141 (i.e., 54\%) of positively polite speech acts generated by the female users and 119 (46\%) examples of positive politeness produced by the male users. Thus, already at this stage it may be noted that there is a greater tendency to make use of positive politeness strategies on the part of women, although indeed the difference is not huge. It might be an indication that, as in the case of emotional aspects of language analysed in the email communication (cf. Dąbrowska 2007a) one of the primary uses of which is that of maintaining social relationships, women and men do not differ so significantly in terms of the language strategies selected as it might be the case in public contexts (cf. Holmes 1995).

The analysis presented below will focus on the characteristics of the variety of speech acts which were identified in the posts as carriers of positive politeness, and notably on their numbers, their use across the gender groups, and the more specific traits which might possibly characterise their use by the two genders. More specifically, the speech acts which were identified as markers of positive politeness in the Facebook language samples could be divided into 7 general categories, i.e. 1. wishes, 2. thanks, 3. praises, compliments and congratulations, 4 . expressions of positive hope, 5. expressions of interest, 6. expressions of a wish to meet, and 7. miscellaneous speech acts (comprising expressions of satisfaction, promises, and invitations).

\section{Wishes}

In keeping with my original assumptions, wishes constitute the largest portion of manifestations of positive politeness, since Facebook itself encourages users to send each other wishes by sending them reminders of their friends' birthdays. Thus, the number of wishes, the overwhelming number of which were birthday wishes, amounts to 78 (70 birthday wishes and 8 wishes concerning other events), i.e. $30 \%$ of all the positively polite speech acts. This figure, surprisingly, can be split into as many as 46 wishes sent by males and only 32 sent by females. This group, however, represents one of only two speech acts (the other being invitations, included in the miscellaneous category) in terms of which the male Facebook users exceeded the female ones in terms of attending to the addressee's positive face, and constitutes as much as $42 \%$ of all the manifestations of positive politeness (divided into the above-mentioned 7 categories) identified in the posts written by men vs. only $24 \%$ of the positively polite speech acts found in the posts produced by women. It is believed that the Facebook's "nudging" its users in order to send wishes to their contacts is partly responsible for the high number of wishes found in the case of men, considering that the remaining 58\% covers all the other 6 categories of speech acts, so the distribution of various strategies of positive politeness in the case of men is markedly uneven. Also, the fact that only $17 \%$ of them are more elaborate structures going beyond the traditional Happy birthday phrase (viz. $31 \%$ in the female posts) is also to be noted. The overview of the forms of wishes used by the male Facebook users singles out the phrase Happy birthday $X$ (where $\mathrm{X}$ stands for the name of the addressee) as the most numerous one, exemplified by 23 posts, occasionally also in the abbreviated CMC language, viz. Happy Bday $X$, as well as Happy belated birthday $X$. This group dif- 
fers just slightly from an even simpler one, i.e. Happy birthday, occasionally followed by a smiley, used 8 times by men. The remaining group covers a variety of forms, viz. Many very happy returns; Many happy returns mate; All the best, have a good one; Hooray for your birthday; Hip hip hoorah for you and much love from me!; Belated hippo birdie 2 $u$; Enjoy your special day!,...And yet another year younger.... As indicated above, occasionally the wish element got extended by some additional birthday-related comment. In the case of the posts written by the males those may be represented by the following: Happy birthday X. Have a great day and a blessed year!; Happy birthday X! Have a great day with all your family and a year ahead; Happy birthday X. All the best. Finally, the remaining group of wishes is small ( 5 items) and concerns a variety of things, e.g., Eid Mubarak to you too (on the Muslim celebration of Eid); Hope you have a gr8 wkend; Good wishes; Good luck; Love to your tribe. Thus, it may be seen that the variety in terms of the structures used and the meaning expressed is fairly limited, and otherwise the users resort to the most typical, traditional phrases.

The examination of the posts written by women demonstrates a smaller number of the expressions of wishes, but a greater variety of those in terms of the form they have taken. This time the primary choice is the simplest form Happy birthday, used 13 times, including also Belated happy birthday (1), yet this phrase is more often than in the case of men followed by another sentence with some additional wish. Second to this is the phrase Happy birthday $X$ with its 10 uses, also sometimes followed by another sentence. The phrases which represent some variation of the form are exemplified by 5 posts, viz. Have an unreal birthday!; Happy birthday from all of us; Happy $18^{\text {th }} X$; Hope you have an enjoyable celebration; Have a super first in (country) celebration. It may thus be seen that the variants are slightly more traditional and also more emotional than those used by some men - the latter, on the other hand, showed a greater tendency towards using more humorous expressions. As said above, more women chose to go beyond just the expression of the wish and added some additional phrase to enhance the emotional value of the wish. These took a variety of forms, e.g., I hope you have a lovely day; Best wishes for the year ahead; Just for you!; Happy memories of kangaroos and cold in (name of a city); Have a great day but be careful!; but what stood out most in terms of the frequency were some more emphatic additions like Love; Love and hugs!, Love you both; Lots of love!, Love from us both!, Much love (in 7 wishes), which were missing in the posts written by men. Another, seemingly unimportant feature, which, however, was found only in the wishes offered by women (apart from other speech acts analysed) was the use of the traditional $\mathrm{x}$ or $\mathrm{xxx}$ as a symbol of a kiss - they were found in as many as 12 posts expressing wishes written by women, but in none whatsoever among those written by men (cf. Dąbrowska forthcoming), which is an undeniable sign of affection, as one does not use this device if one does not want to stress positive feelings towards the other person, and therefore, a manifestation of positive politeness as well. Finally, in order to cover the question of wishes, it needs to be added that women also sent wishes to their friends on other occasions, though these were very limited ( 3 items), i.e. Happy 2 nd anniversary!; Stay safe, X!, Good luck, X, you deserve to get a fantastic grade. In summary of this speech act it therefore needs to be stressed that, albeit there were numerically more 
posts with wishes written by men, the female way of offering wishes tends to be more elaborate and affectionate than that of men, and this may be marked by both some additional comments aiming to stress the importance of the occasion or show others how much they are loved, or by the use of the xxx in order to stress the emotional bond with that person and show how much the female senders liked them. When it comes to any possible age differences in relation to the age groups the post authors represented, most likely due to the fact that wishes tend to be highly conventionalised, as the above analysis has demonstrated, no particular distinctions could be found.

\section{Praise, Compliments and Congratulations}

Telling someone that we admire them or the items which belong to them or else the activities performed by them is certainly one of the principal ways of showing positive politeness towards that person. Also, the Facebook context, with the help of which the users share with their contacts what they have done, what has happened to them, etc. greatly encourages some sort of response, and, as the overview of Facebook posts has proved, these are hardly ever negative responses. Because of the nature of Facebook, which is meant to connect rather than divide people, the users would rather withhold any reaction at all when disagreeing with or disapproving of what another person has written on their wall than comment on it in outwardly negative terms. On the other hand, when liking what the other person writes, the user has a choice of either marking it with the thumbs up symbol, by far the most popular way of showing positively polite attitude towards others, or writing something below the original post. The comment may obviously focus on the factual aspect only, however, the present analysis has proved that in addition to that Facebook friends very often say something nice about what the author has written. It is therefore self-explanatory that expressions of praise, compliments and congratulations, which I have decided to put together due to their similar nature, occupy the second highest position on the list of the most frequent positively polite speech acts to be found on Facebook, after wishes. However, unlike in the case of wishes, which are induced by Facebook, and ignoring of which may be viewed as an outward manifestation of negative feelings towards or about the birthday addressee, as giving wishes is an expected social custom, in the case of reacting to the other persons' posts the recipients are free to take no steps at all, and this entails no anathema or negative feelings. Therefore, when they do decide to respond to the posts, and what is more, when they respond by praising, complimenting or congratulating, the positive value of such a response is particularly high.

The overall number of praises, compliments and congratulations for both groups consisted of 49 examples. Out of this figure $15(31 \%)$ were offered by men, whereas as many as 34 (i.e. $69 \%$ ) were found in the posts written by women. This is one of the three categories of positively polite speech acts (beside expressions of interest in the addressee and expressions of hope for another meeting) where the discrepancy between the two genders was most visible.

Among the objects of praise those which evoked a very similar number of reactions from both genders were various items belonging to the post authors, and notably photos or things they were the authors of (e.g. a cake, a decoration of a coffee jar). In this cate- 
gory men wrote 7 posts and women 8 , viz. great photo; that is a really beautiful picture; great photo X; wonderful picture J, vs. I like your profile picture; great pic; nice picture of your mum; looks great!; best dressed coffee I've ever seen. The fact that both groups chose to praise those objects in a similar way proves that complimenting others on their belongings appears to be safest of all, least face-threatening. A similar approach, though of a much lower frequency, can be found in the case of ideas that the post authors expressed, and which were offered by men 4 times, and by women -3 , e.g. Sounds like a good plan; That's cool, Nice one, X; vs. Really like your idea; Fantastic; Wonderful. What needs to be noted here is the use of informal language and structures, illustrated by, e.g. the deletion of the subject phrase of the sentence, the use of common, often "empty" adjectives, etc. The situation appears to be similar in the case of praising events, although there seems to be a slightly greater discrepancy between men ( 2 praises) and women (6 praises). Some examples to be quoted here are: Hey X, nice memory! vs. It was lovely X J, I was impressed by your Long Walk last year; Had a great time with X; Great working with you.

The aspect where the greatest differences between the two genders are to be observed, however, are praises, congratulations and compliments offered to the other in terms of their achievements (men -2 , women -11$)$, looks (men -0 , women -3$)$ and also people (men -0 , women -2$)$. The first of the three is particularly striking, as it would have seemed only natural to commend someone on what they did or congratulate them on their success. Women do it quite readily, viz. Congratulations, lovely lady! Well done for getting a fab degree, can't wait to see the pics; Awesome - congratulations to you both $J$ xxx; Congratulations to you too as I gather you are now Dr X!; Well done you!; Well done to X on getting on to her college course; Well done to X!; Wehay! Well done to X!; Congratulations on your graduation day! vs. Well done for getting the grades fresh ones!; Congrats X! in the case of men. Congratulating someone on their achievements, as can be seen, is typically accompanied by high emotionality, which is reflected in may examples by means of exclamation marks, smileys and, in the case of women, xxx. Female Facebook users appear to offer such comments to their contacts freely, as it does strengthen their bonds of friendship with the others. The comparative lack of such expressions on the part of men may possibly stem from some hidden feeling of jealousy - men on the whole like to compete against each other (cf. Tannen 1990), so possibly acknowledging the other person's success may not come to them easily (cf. also the use of compliments in Holmes (1995)).

If congratulating others on their achievements is considered face-threatening, then complimenting others on their looks is an even greater danger to the male face, as studies of some materials have demonstrated (cf. Herbert 1989, 1990; Holmes 1995). Men hardly praise the other person's looks - it is a risky action with regard to a female addressee, as it may be perceived as an act of sexual harassment, and it is even more risky when addressed to another man, as then the speaker may be accused of homosexual orientation. That is why the collected material contains only a few comments from women, viz. Nice hair. x; you look gorgeous, X!, X, you look like such a cool customer!, and none from men. In a similar way, praising people for what they are like as people (not just their 
looks) may lie more in the domain of women, hence the two additional comments offered by female Facebook users, viz. I have such wonderful friends and You are very kind. Thus, the overview of the use of this group of speech acts shows unmistakably that, to quote Holmes's (1993) title she used for one of her papers, "[New Zealand] women are good to talk to," as they strive to make their interlocutor feel nice and appreciated (cf. also Coates 1996).

\section{Thanks}

Thanks are also on the whole used as markers of positive politeness in that they express gratitude, i.e. they indicate approval of the other person. Unlike the two previous speech acts, thanks, represented by 45 examples, present little difference in terms of their use by the two genders, as the male users thanked their Facebook friends for something 22 times, and women -23 times. Thus, the figures in both cases are fairly high when compared to the numbers of various other speech acts used here. This may be caused by the fact that thanking is perceived as a primary sign of good upbringing and politeness in the very conventional sense. One is expected to thank the speaker on receiving gifts (cf. Brown and Levinson 1987/1994), here verbal gifts, as e.g. wishes of various kind or praises and compliments discussed above.

On a closer examination of the thanking strategies opted for by Facebook users it may be noticed that the options are not very numerous, and with a slightly lower number of thanks used by men there is somewhat greater variation in the forms here $(5$ categories used by men vs. 4 used by women). The form that by far exceeds the others is the simplest thanking formula, viz. thanks, which may stand alone or be followed by some more elaborate phrase. It was used by men 14 times, and by women as many as 18 times, e.g. Thanks!; Thanks X!; Thanks for remembering!; Thanks for the email; vs. Thanks!; Thanks X; Thanks friends; Thanks guys; Thanks for inviting us; Thanks to everyone that came on Saturday; Thanks for the likes and reading the posts!; Thanks for the invite; Thanks to all of you for the surprise birthday \& leaving dinner!. Occasionally the word thanks was modified to make the meaning more affective, which in fact was found more often in the phrases used by men, viz. Hi thanks a lot!; Hi X thanks a lot; Hey X thanks a million (such variants were used 4 times) as opposed to only one phrase of this type used by a woman, i.e. Thanks so much. Next to the most neutral and at the same time informal word thanks the more official thank you was also found, usually with the complement to follow, but it was used far less frequently than the above option, i.e. twice by men and three times by women, viz. Thank you; Thank you, I will vs. Thank you everyone for the birthday wishes; Thank you for the 'congratulations' texts; Thank you for being there for me when I need you. It may be noticed, therefore, that the full phrase is used to carry thanks in slightly more serious contexts where the use of thanks might be perceived as too neglectful. In addition to the bare form of thank you men decided to use two more options which are again more emphatic as a result of modifying the phrase by the intensifying adverbs so and very, thereby making the expressions of thanks stronger but also more formal sounding, i.e., Thank you very much; X thank you so much for your greetings. On the other hand, only one person, this time a young woman, went for a much 
more colloquial option, typically found with the younger generation, i.e. cheers, as in Cheers ma, you too! To sum up, it may, therefore, be stated that thanks, although quite abundant, but simple in their form, are used by Facebook users probably more out of convention; any more affectionate form of thanks would have probably been reserved for a more personal, one-to-one message.

\section{Expressions of Positive Hope}

The next item on the list of the speech acts which carry positively polite meanings towards one's friends are what I have decided to call expressions of positive hope, as I was quite struck by the number of expressions addressed towards a friend which started with [I] hope that... and then they were followed by some sort of an indirect wish about either the present situation (which appeared to be the most numerous), the future or, least often, about the past. The numbers, similar for both genders, one more time showed a slight bias towards the female users. They were used 34 times in all - 15 times by men and 19 times by women. Both groups had almost the same numbers for the expressions of hope about the present ( 9 and 10, respectively), about the future ( 5 in each group), only with regard to the expressions of hope concerning some past event women exceeded men more ( 4 for women vs. 1 for men). The structure of those is similar, i.e. for the present: I hope that all is well with you and that you are doing well; Hope all is well with you; Hope you are all well; I hope you and yours are flourishing; Hope you are having a great time (men) vs. Hope you are doing OK, Hope you are all well and lovely; I hope you and your family are well; Hope that you are making the most of it in your new home; Hope you're taking full advantage of chilling out before the job starts!!! Xx; Hope life is good; Hope all well at hospital? (women); for the future Hope we can see you sometime; I hope to see you or talk to you soon; Hope it's a great day and a blessed year X; Hope u hve a gr8 wkend (men) vs. Hope to do it again some time soon; I hope you have a great day $x$; I hope we will all come see you; Hope you have an enjoyable celebration (women); and the past Hope X was OK for you (men) vs. Hope you had a great day; Hope you all had a good time; Hope you celebrated (women). Thus, the overview of the collected examples demonstrates that the senders show their addressees that they like them and care for them as they express all those positive hopes with regard to their friends. The frequent use of this strategy proves to be a specially useful device in that it shows that others are important to us, that we care about them.

\section{Expressions of Interest in Others}

The number of elements in this category is significantly smaller than in the abovementioned ones, giving us 20 items in all, but this strategy is worth mentioning in greater detail as one of those where the gender difference may also be noted, albeit on a small scale. Out of the overall number only 7 examples of this speech act were found in the posts written by men, and as many as 13 in the posts written by women. Expressing interest is most typically shown through questions about the other's well being, less often by stating that we are missing that person. The first option may be illustrated by the following posts: How are you/U; How and where are you these days?; All OK with you?; 
How are you celebrating tonight? vs. How are things with you; How is your voice?; The second category of speech acts illustrating this strategy here are I sometimes wonder about you and what you are doing; Thinking of you often (men) vs. Missed you this weekend; I miss you already; I'm missing you too; Miss you too; Thinking of you (women). The remaining few are Much sympathy; Send photos of the new place!. The overall examination thus shows that there is a significant numerical difference between the two genders, with women as natural carers and affectionate persons having expressed interest about the others more. What is particularly striking is the use of phrases like Miss you too, I miss you already, I'm missing you, etc. Men never ventured such an open display of emotionality.

\section{Expressions of a Wish to Meet}

This category of items which fall under the strategy of positive politeness is difficult to label. In other genres, notably letters and email messages, they would most likely be described as closing turns, as they usually come at the end of the message. However, a closing turn, strictly speaking, would include expressions of good-byes which might or might not be complemented by additional elements like those of expressing a wish to meet again. I am interested in that last item in particular, since expressions which contained such type of message constituted a visible part of the collected material - they, however, do not always come at the end of the post or a whole sequence of posts, but may constitute a separate item, and the posts may not contain farewell words at all, hence the difficulty with their classification.

This group of positively polite phrases, which altogether consists of 17 items, also belongs to the types of expressions which bring out differences in the Facebook behaviour of men and women. Whereas men expressed a wish to meet with the addressee again 6 times, women indicated their willingness to see the person again or soon 11 times. Thus, although the group is altogether small, the numerical values still mark the gender differences quite clearly. The expressions used by men are not only less numerous, but also less emphatic, and there is hardly any difference in how they approach both male and female addressees. The expressions recorded are See you in a few weeks; See you soon; Look forward to see you in X; I long to see you and the family; Much looking forward to see you in September and looking forward to welcoming all of the freshlings to $X$. The expressions used by women, both to female and male addressees, may make use of neutral forms, as e.g. See you Monday/Saturday/on the $3^{\text {rd }}$; Looking forward to seeing you soon; and we will look forward to seeing you whenever you make it; Look forward to catching up with you and X soon, but some of the expressions, in particular those written on the walls of other females, take a more affective form, e.g.: Can't wait to see you xxx, And I can't wait to meet up with you in X. In conclusion, making use of this type of expressions makes the overall message particularly pleasant to read, they are therefore a useful marker of positive politeness, and making such expressions more emphatic, which is typically the case of women, make the speaker's intention sound particularly genuine. 


\section{Miscellaneous (expressions of satisfaction, promises, invitations)}

The final category of items which can be classified as markers of positive politeness in the collected material includes the remaining types of speech acts whose number was much lower than that of the expressions discussed above, and for this reason they have been classified together. There are 17 items in all, and they fall into three categories: expressions of satisfaction connected with the other person (best represented - 9 items altogether, spread equally between the two groups, i.e., 4 written by men and 5 by women), promises ( 4 items, 2 written by men and 2 by women) and, finally, invitations (4 items, all produced by one man). A brief discussion of each is as follows:

- expressing satisfaction in connection with the other person (i.e. about meeting with them or experiences related to them). Most of them do relate to the fact that the author of the post had a chance to meet with the other person. Examples of the strategy are as follows: Glad to meet you at X; Glad you can come up man!; Glad you're enjoying it out there! and Glad to see your film again at $X$ a couple of days ago, which were written by men, as opposed to It was nice to see you this summer; Nice to see you in spite of the circumstances; Glad you like it lol $x$; Lovely to see X's new set up and visit friends in X; Was delighted to hear you and $X$ are moving in produced by women. Such a small group does not allow for much generalisation, it might be, however, possible to conclude that if men decide to make a comment of this type, it will refer to the most obvious and least facethreatening subject as a meeting, while women might show a greater inclination towards expressing happiness about a variety of aspects connected with the other person, which on the whole creates a pleasant atmosphere of approval.

- promises: making promises is to reassure the addressee that something they care about will happen, it appeases them, and as such may be considered to be a type of a gift that Brown and Levinson (1987/1994) speak about. There were very few promises made on Facebook, however. It might be that promises are more readily used in speech, and not so much in spontaneous writing in a public context, especially in CMC. The four items found in the material are: Will do my best to get over and see you; We promise to leave at 9 before the X starts (written by men) and I will be in touch once we have the opening night; I will be in touch soon about next week (written by women). Thus, as can be seen, they concern some arrangements made earlier. Here making a promise acts as an additional bond strengthening friendship, as the senders want to show that they care about the other person's feelings, hence their classification as a positive politeness strategy.

- invitations: this speech act is certainly a very clear marker of positive politeness since, when we invite someone over for a visit, we show particularly strongly how much we like or admire the person - inviting someone over goes further than just uttering kind words, it also entails quite a lot of action, often troublesome for the inviter. It is probably for this reason that invitations were generally not found, except for one person, as they, however encouraging they may sound to the invitee, are also very face-threatening to the speaker. The fact that four items of this speech act were found in the case of one man is connected with his life circumstances (he and his wife have just moved to a new place and after settling down there they were particularly keen on having their friends 
over). Hence such expressions as When are you and $X$ coming for a visit?; When are you coming to X; How about coming to X for a holiday in our little guest house which is going up next week?; We look forward to a visit from you both, seriously! In order to evaluate the use of this speech act properly, however, it would be necessary to find other persons experiencing similar life circumstances. The lack of such an opportunity forces us to merely take note of the option.

\section{Conclusion}

The above discussion constituted a scrutiny of language strategies which may be used to indicate positively polite behaviour, one of four types of politeness put forward by Brown and Levinson (1987/1994) which appears to be particularly visible in a popular form of CMC which social networks nowadays constitute. As many as 9 different linguistic strategies (grouped into 7 categories) were found to express this specific type of meaning, thereby stressing the predominantly phatic character of the CMC Facebook communicative style and function.

The brief analysis of the male and female behaviour recorded in the context of Facebook, an example of a social network, has managed to demonstrate that, in keeping with the initial assumption, the behaviour of native English speakers does show divergent tendencies in terms of the gender of the users. Out of the 9 categories of speech acts analysed, as many as 5 demonstrated a higher frequency of use on the part of women, and in particular in 3 of them, i.e. praises, compliments, congratulations, expressions of interest about the other, and expressions of a wish to meet were almost twice as often used by women than by men.

As regards the remaining 4 types of speech acts, two of them, i.e. thanks and promises, respectively, did not show any significant divergence in terms of distribution between the two groups. The last two groups, i.e. wishes and invitations turned out to have been more often used by men, although for the lack of comparable context the category of invitations must be treated just as a possibility to be tested in other contexts. As regards the high number of wishes produced by men, it is possible that the Facebook reminders tend to make the male users more keen to fulfil the expectations. It is probably similar in the case of thanks (in the case of which the two groups behaved almost identically) their frequent use might result from the fact that it is a kind of a social obligation not only to acknowledge the other person's birthday but also thank for wishes.

In the analysis of the material no particular differences concerning the age of the post authors were found, with the numbers of particular types of expressions distributed among the three age groups very evenly. On the other hand, however, an additional difference could be found in terms of gender, namely a much greater emotional character of the posts written by women. This could be seen both in the more affective character of posts indicated by suitable structures and vocabulary used and the liberal use of the $x x x$ to end the posts. Hardly any use of the above was found in the group of posts written by men.

To sum up, it is to be concluded that male and female native English speakers do tend to behave somewhat differently in an informal or semi-formal context, of which 
Facebook appears to be a particularly good example. It remains to be tested whether a similar tendency is also to be found in the case of other cultural and ethnic groups as well as in other language contexts.

\section{References:}

1. Bing, J.; Bergvall, V. (1996) The Question of Questions: Beyond Binary Thinking. // Rethinking Language and Gender Research: Theory and Practice. / Ed. by V. Bergvall, J. Bing, and A. Freed. London: Longman.

2. Brown, P.; Levinson, S. (1987/1994) Politeness. Some Universals in Language Usage. Cambridge: CUP.

3. Cameron, D. (1995a) Rethinking Language and Gender Studies: Some Issues for the 1990s. // Language and Gender: Interdisciplinary Perspectives. / Ed. by S. Mills. Harlow, Essex: Longman.

4. Coates, J. (1993) Women, Men and Language. London: Longman.

5. Coates, J. (1996) Women Talk. Oxford: Basil Blackwell.

6. Dąbrowska, M. (2007 $)$ Modifiers in Male and Female Expressions of Emotions. // B.A.S. British and American Studies. / Ed. by H. Parlog. Timisoara: EUV Editura Universitătii de Vest.

7. Dąbrowska, M. (2007d) Female Acts of Identity. // Journal of Languages and Translation. Vol III - No II, Part II A Special Issue for the Proceedings of the Fourth International Conference of the Faculty of Al-Alsun, Minia University "Preserving Linguistic and Cultural Identity in the Age of Globalization. / Ed. by A.M. Kamal. Minia: Minia University Printing House.

8. Dąbrowska, M. (2007e) Male and Female Strategies of Communication in E-mail Discussion Groups. // Armenian Folia Anglistika. International Journal of English Studies 2(4)/2007. / Ed. by S. Gasparyan. Yerevan: Lusakn.

9. Dąbrowska, M. (2011) Hindi-English Code-switching as a Community of Practice Marker. // English in Action. Language Contact and Language Variation. / Ed. by E. Willim. Kraków: Kraków Society for Education AFM Publishing House.

10. Dąbrowska, M. "You Look Fab on This Pic!" Gender and Age in Facebook Communication. // Languages, Literatures and Cultures in Contact: English and American Studies in the Age of Global Communication, Vol. 2: Language and Culture. / Ed. by M. Dąbrowska, J. Leśniewska, B. Piątek, forthcoming.

11. Eisikovits, E. (1987) Sex Differences in Inter-Group and Intra-Group Interaction Among Adolescents. // Women and Language in Australian and New Zealand Society. / Ed. By A. Pauwels. Sydney: Australian Professional Publications.

12. Eisikovits, E. (1988) Girl-Talk/Boy-Talk: Sex Differences in Adolescent Speech.// Australian English. / Ed. by P. Collins, D. Blair. Brisbane: University of Queensland Press.

13. Fraser, B. (1990) Perspectives on Politeness. // Journal of Pragmatics 14 (2). Amsterdam: Elsevier. 
14. Goffman, E. (1967) Interaction Ritual: Essays on Face-to-Face Behavior. Garden City: New York: Doubleday.

15. Herbert, R.K. (1989) The Ethnography of English Compliments and Compliment Responses: A Contrastive Sketch. // Contrastive Pragmatics. / Ed. by W. Oleksy. Amsterdam: John Benjamins.

16. Herbert, R.K. (1990) Sex-Based Differences in Compliment Behaviour. // Language in Society 19. Cambridge: Cambridge University Press.

17. Holmes, J. (1993) New Zealand Women Are Good to Talk to: An Analysis of Politeness Strategies in Interaction. // Journal of Pragmatics 20(2). Oxford: Elsevier Science.

18. Holmes, J. (1995) Women, Men and Politeness. Harlow, Essen: Longman.

19. Janney, R.W.; Arndt, H. (1992) Intracultural Tact Versus Intercultural Tact. // Politeness in Language: Studies in Its History, Theory and Practice. / Ed. by R. Watts, S. Ide, K. Echlich. Berlin: Mouton de Gruyter.

20. Lakoff, R. (1975) Language and Woman's Place. New York: Harper and Row.

21. Leech, G.N. (1980) Explorations in Semantics and Pragmatics. Amsterdam: John Benjamins.

22. Leech, G.N. (1983) Principles of Pragmatics. London: Longman.

23. Mills, S. (2003) Gender and Politeness. Cambridge: CUP.

24. Stockwell, P. (2002) Sociolinguistics. / A Resource Book for Students. London and New York: Routledge.

25. Swann, J. (2000) Gender and Language Use. // Introducing Sociolinguistics. / Ed. by R. Mesthrie, J. Swann, A. Deumert, W.L. Leap. Edinburgh: Edinburgh University Press.

26. Tannen, D. (1990) You Just Don't Understand: Women and Men in Conversation. New York: William Morrow.

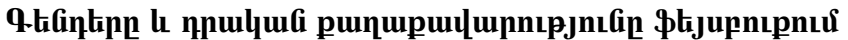

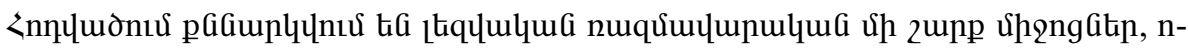

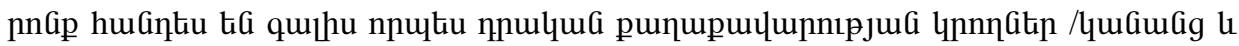

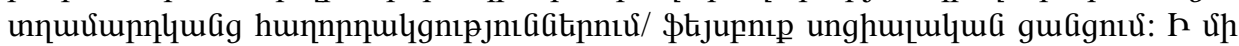

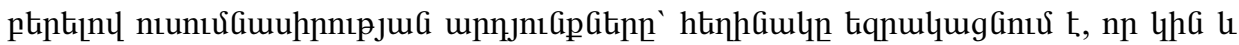

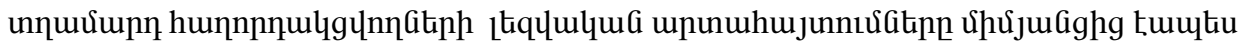

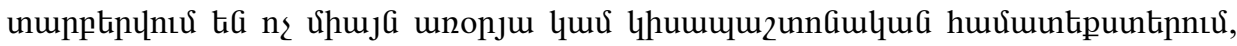

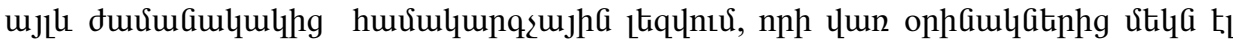
\$tjupnıp unghupulqua guagh $\mathrm{t}$ : 